\title{
Environmentalism in the realm of Malaysian novels in English
}

\begin{abstract}
Malaysian literature in English occupies a peculiar position in the nation-building discourse. This is due to the recognition of literature written in Malay as the national literature, following the National Language Act 1967 that recognized Malay as the national language. Literatures written in languages other than Malay, including English, are relegated as "vernacular" literatures and are often left out in the discourse of nation-building. Some, those who may not be so inclined as to acknowledge the importance and the necessity of Malaysian literature in English, might dismiss the notion that it has anything to communicate about the state of the environment in Malaysia. These individuals are mistaken - an unfortunate aspect of this literature that is lost on the casual reader (or the non-reader) is the alignment of some novels to the key moments in the history of environmentalism in Malaysia. In the realm of Malaysian literature in English, writers have written about environmental activism - although little attention has been given to this area in the local literary-critical practice. In this chapter, I examine and critique four contemporary Malaysian novels in English: Keris Mas' Jungle of Hope (2009), Yang-May Ooi's The Flame Tree (1998), KS Maniam's Between Lives (2003), and Chuah Guat Eng's Days of Change (2010). I analyze the environmental politics, past and present; the plurality of relations and struggles depicted; and the solutions that these works present to promote sustainability. This chapter yields a keen understanding of irresponsible environmental degradation as well as illuminate agency and transformation. More importantly, it places Malaysian literature in English at the core, thus demonstrate the indispensability of these works in the history of environmentalism in Malaysia.
\end{abstract}

